\title{
EFFECT OF PEER-LED AND TEACHER-LED EDUCATIONAL INTERVENTIONS ON DEPRESSION-RELATED KNOWLEDGE AMONG IN-SCHOOL ADOLESCENTS IN OGUN STATE, NIGERIA
}

\author{
Uzoechi Chinomso A. ${ }^{1}$ and Amosu Ademola M. ${ }^{2}$ \\ ${ }^{1}$ Department of Public Health, Babcock University, Ilishan-Remo, Ogun State, Nigeria. \\ Email: cuzoechi05@gmail.com \\ ${ }^{2}$ Professor, Department of Public Health, Babcock University, Ilishan-Remo, Ogun State, \\ Nigeria. Email: amosua@babcock.edu.ng
}

Cite this article:

Uzoechi C.A., Amosu A.M (2021), Effect of Peer-Led and Teacher-Led Educational Interventions on DepressionRelated Knowledge Among in-School Adolescents in Ogun State, Nigeria.

International Journal of Public Health and Pharmacology 1(2), 70-83. DOI

10.52589/IJPHP-QJOZLVEF.

\section{Manuscript History}

Received: 23 Oct 2021

Accepted: 9 Nov 2021

Published: 25 Nov 2021

Copyright () 2020 The Author(s). This is an Open Access article distributed under the terms of Creative Commons AttributionNonCommercial-NoDerivatives 4.0 International (CC BY-NC-ND 4.0 ), which permits anyone to share, use, reproduce and redistribute in any medium, provided the original author and source are credited.
ABSTRACT: The study aimed to determine the effectiveness of peer-led and teacher-led educational interventions on depression-related knowledge among in-school adolescents in Ogun State, Nigeria. The study utilized a quasi-experimental design comprising one control group and three experimental groups. The population of the study was 120 in-school adolescents selected using the multistage sampling technique. A validated semi-structured questionnaire was used for data collection. The findings revealed that the adolescents' level of depression knowledge had a significant increase after the intervention. The teacher-led group had greater knowledge scores (mean difference $=14.87$; effect size $=5.222 ; t=19.943$; $p=0.000)$. In conclusion, the teacher-led educational intervention was very effective in improving the level of adolescents' depression knowledge in Ogun State. It is recommended that teachers are empowered in the country to be able to provide adolescents with the necessary support in which they play the role of mentors in schools.

KEYWORDS: Depression, Adolescents, Knowledge, Peer-led, Teacher-led, Health Belief Model. 


\section{INTRODUCTION}

Depression is one of the most frequent yet under-diagnosed mental health issues in children and adolescents; the repercussions are far-reaching and manifest later in life in the social, psychological, and intellectual domains if not identified and treated early (National Institute of Mental Health [NIMH], 2018). Low- and middle-income countries (LMICs) have insufficient human and infrastructural resources to provide mental health care services (Saxena, Thornicroft, Knapp \& Whiteford, 2017). Depression, like other mental illnesses, is frequently disregarded or ignored in most communities around the world, particularly in African societies, and it is a major mental health disease condition that affects people of all ages with adolescents being no exception (Dapaah \& Amoako, 2019).

Globally, more than 394 million people of all ages suffer from depression, a prevalent mental disorder and a leading underlying condition that contributes significantly to the global disease burden (James, Abate, Abbai, Abay \& Abdollahpour, 2018; Aluh, Abba \& Afosi, 2020; WHO, 2020). After adjustment for age using the 2001 census data, a large population-based study from South India reported that the total prevalence of depression was 15.1\% (Goyal, Kohli, Kishore \& Jiloha, 2013). According to research findings on depression literacy among adolescents, there is a lack of knowledge of depression and no appropriate source of depression-related health-seeking (Burns \& Rapee, 2017).

Nigeria is a developing country, and therefore, it is exposed to a wide range of events that can affect people's mental health. Fewer than $10 \%$ of people who suffer from mental illnesses like depression receive medical care in a year, according to estimates (Ekwe \& Ohuakanwa, 2020). According to a published research conducted in Nigeria's South-West, there is an urgent need for school-based interventions aimed at improving knowledge, identification and symptoms of depression as well as promoting appropriate health-seeking among adolescents (Adeosun, 2016). Mogaji (2017) indicated that a large percentage of adolescent participants $(80 \%)$ misidentified high self-confidence as a symptom of depression and had insufficient knowledge of depression.

Education has been identified as an effective approach for increasing knowledge and decreasing negative attitudes regarding mental health illnesses including depression (Naylor, Cowie, Walters, Talamelli \& Dawkins, 2019). After being exposed to educational programs, young people's attitudes and perceptions about mental health illnesses such as depression improved (Labinjo, Serrant, Ashmore \& Turner, 2020). As a result, educating adolescents about depression is critical.

The Health Belief Model (HBM) was used in this research. It is a cognitive model that posits that an individual's decision to perform a certain behavior is dependent on the individual's benefits of the behaviour itself and variables, one of which is knowledge. It is one of the most commonly used theories in health education and health promotion to explain and predict healthrelated behaviours (Hochbaum, 1958; Rosenstock, 1966; Becker, 1974; Sharma \& Romas, 2012).

The purpose of the study examined how peer-led and teacher-led educational interventions affected depression-related knowledge among secondary school students in Ogun state, Nigeria. The study hypothesized that there would be no significant difference in the level of 
in-school adolescents' awareness of depression at baseline and after an 8-week follow-up period.

\section{METHODOLOGY}

\section{Study Design}

The study utilized a quasi-experimental design which comprised three experimental groups and one control group using the quantitative approach. Health education programme focused on depression-related knowledge was delivered to the three experimental groups, and a placebo was delivered to the control group. The intervention was for a duration of 6 weeks which was in three sessions, lasting for an average of 120 minutes. At baseline, data were collected before the program and at 6 weeks post-intervention in both the experimental and control groups.

\section{Study Area}

The study was conducted in four (4) public secondary schools that were selected from four local government areas (LGAs) in Ogun State, which are Remo-North, Ijebu-Ode, Odogbolu and Ijebu-North respectively. The communities employed for this study were at Ipara, Odonoko, Idowa and Mamu, where the indigenes are mostly traders and farmers.

\section{Study Population}

The target population for this study was in-school adolescents in selected public secondary schools in Ogun State, Nigeria.

\section{Inclusion and Exclusion Criteria}

Those included were students who reside in Ogun state, Nigeria, fully registered students of the schools as at the period of the intervention, male and female students between the ages of 10-19 years, students who gave their assent willing to participate, parents who gave consent for their children to participate and teachers who were interested and were willing to participate in the study. Those excluded were students who did not reside in Ogun State, Nigeria, students who had not been fully registered in the school as at the period of the intervention, students below and above the age bracket (10-19 years), students who did not give their assent and were not willing to participate, parents who did not give consent for their children to participate in the study and teachers who were not interested and were not willing to participate in the study.

\section{Sampling Procedure}

Random sampling technique was used for the selection of in-school adolescents from public secondary schools in Ogun State. Out of the three senatorial districts in Ogun State, Ogun East was purposively selected. This is because it is made up of about $50 \%$ out of the 20 local government areas (LGAs) in Ogun State. Four LGAs were selected using the random sampling technique from Ogun East senatorial district by balloting, and were assigned into four groups. Three schools were randomly selected for the intervention groups and a school was selected for the control group from selected LGAs.

\section{Sample Size Determination}


The sample size that was used for this study was derived from the computation, using a level of significance of $95 \%$ and $80 \%$ power. There was no given prevalence estimate of depressionrelated knowledge among in-school secondary students in Ogun State, Nigeria. Thus, the sample size was derived using prevalence at $50 \%$ :

$$
\mathrm{N}=\frac{\left(\mathrm{Z}_{\alpha}+\mathrm{Z}_{\beta}\right)^{2} \times \mathrm{P}_{0}\left(1-\mathrm{P}_{0}\right)}{\left(\mathrm{P}_{1}-\mathrm{P}_{0}\right)^{2}}
$$

where $\mathrm{N}$ is the minimum sample size per group

$\mathrm{Z}_{\alpha}=$ standard normal deviation at $95 \%$ confidence interval (1.96)

$\mathrm{Z}_{\beta}=$ statistical power at $80 \%$ confidence interval (0.84) (power to detect changes in the outcome variable and avoid type II error)

$\mathrm{P}_{0}=$ prevalence at $50 \%=0.5$

$\mathrm{P}_{1}=80 \%$ (desired level of outcome variable)

$\mathrm{N}=\frac{(1.96+0.84)^{2} \times 0.5(1-0.5)}{(0.8-0.5)^{2}}$

$$
(2.8)^{2} \times 0.5(0.5)
$$

$(0.8-0.5)^{2}$

$$
7.84 \times 0.25
$$

0.09

$=21.78 \simeq 22$

The minimum sample size was $22.10 \%$ of the minimum sample size was added to take care of attrition. Therefore, the total number of participants after adding $10 \%$ of $22=22+2.2 \simeq 24.2$ $\simeq 30$. Based on this computation, a total number of 120 participants (30 per group $\mathrm{x} 4$ ) from the four secondary schools were enrolled for this study (indicating 30 people per group).

\section{Instrument for Data Collection}

A quantitative approach consisting of close-ended questions that covered all aspects of the study was used for this research. The instrument was a semi-structured, participant administered questionnaire that solicited information on socio-demographic characteristics and depression-related knowledge among in-school adolescents from selected secondary schools in Ogun State. The same instrument was administered at baseline, immediate post-intervention, and 8-weeks follow-up. 


\section{Study Variables}

The peer-led and teacher-led educational interventions were the independent variables while knowledge on depression was the dependent variable.

\section{Validity and Reliability of Instrument}

Face validity was adopted in validating the questionnaire to be used for the study. This was looked at by the supervisor and lecturers in the department. Item validity was also adopted by ensuring that the items in the instrument were carefully and thoughtfully selected in order for them to operationalize each of the variables they fall under. Construct validity using the conceptual framework (Health Belief Model) was adapted and variables in the instrument were selected based on the objectives of the study using the model.

To ascertain the reliability of the instrument, a pilot test was conducted for internal consistency of the instrument using $10 \%$ of the anticipated sample size from another public secondary school not included in the study, but with same characteristics as the study participants, to check for clarity and understanding. Twelve of the questionnaires were pre-tested among twelve students. The responses that were provided after the pilot study was fused into the instrument. The data collected from the respondents was statistically analyzed using the Cronbach's alpha standard score to test its reliability. The reliability score generated was 0.82 .

\section{Data Analysis}

The data obtained from the study was screened by cross checking each item on every questionnaire to ensure that the respondents answered correctly, and in cases where no response was given, this was treated as missing data. However, the data collected was collated, entered and coded using Statistical Package for Social Sciences (SPSS) version 23. Descriptive (means, standard deviation, standard error) and inferential (ANOVA) statistics were used for the data analysis. A statistical level of significance for the inferential statistics was set at $\mathrm{p}<0.05$.

\section{RESULTS}

A total of 120 adolescents from four secondary schools in four local government areas (LGAs) in Ogun State, Nigeria, were recruited for the intervention. At the start of the study, each intervention and control group had 30 participants. The intervention and control groups both had $100 \%$ response rates at the post-intervention and follow-up points. The distribution of the students' socio-demographic characteristics within the groups was tested for randomization at baseline. The results showed that there was no statistical disparity between the intervention and control groups, according to the findings. The distribution of the students' age, gender, class and religion had no statistical difference (Table 1).

At baseline, the mean \pm SD ages of the adolescents in the teacher-led, peer-led, teacher and peerled, and control groups were $14.43 \pm 2.315$ years, $14.33 \pm 1.605$ years, $14.97 \pm 1.426$ years and $15.43 \pm 1.960$ years respectively (Table 1). A third of the students in the teacher-led group (10; $33.3 \%$ ) were in SSS 2. Equal proportion (23.3\%) of students in the peer-led group were in JSS 2 and while over half were in SSS 1 in the combination group. The control group however had 
the highest proportion of students in the SSS 1 class (Table 1). Regarding the religious distribution, majority of the students across the four groups were Christians while only 5 (16.7\%), 1 (3.3\%), $15(50 \%)$ and $4(13.3 \%)$ were Muslims in the groups respectively (Table $1)$.

The ethnic distribution showed that majority of the adolescents in this study were from the Yoruba ethnic group with a minority from the Igbo, Hausa and other ethnic groups. The marital status of the adolescents' parents was assessed and the results showed that majority of the adolescents were with married parents across the four groups (Table 2).

\section{Baseline Distribution of Knowledge of Adolescents on Depression}

The level of knowledge of adolescents on depression was measured on a 27-point rating scale and grouped into poor (0-13.5) and good (13.6-27). The distribution of the adolescents' overall level of knowledge of depression showed that 19 (63.3\%), 18 (60\%), $17(56.7 \%)$ and $21(70 \%)$ had poor level of knowledge in the teacher-led, peer-led, combination of teacher and peer-led and control groups respectively. The mean \pm SD scores for each of the groups were $11.57 \pm 4.01,13.47 \pm 4.52,12.83 \pm 4.14$ and $12.63 \pm 3.18$ respectively (Table 3). Adolescents' sources of information on depression was high $(30.0 \%)$ in the combined intervention groups - the peer-led and teacher-led educational intervention group (see Figure 1).

\section{Knowledge of Adolescents on Depression at Immediate Post Intervention}

The knowledge of the adolescents on depression was assessed after the intervention was administered and completed. The measure was computed on a 27 -point rating scale with mean \pm SD of $26.20 \pm 0.96,25.20 \pm 1.73,25.70 \pm 1.47$ and $12.70 \pm 3.25$ in the teacher-led, peer-led, peer-led and teacher-led and control groups respectively. The results showed that the highest mean was recorded in the teacher-led intervention group. All the adolescents in the three intervention groups recorded high scores of depression knowledge after the intervention (30; $100 \%$ ) (Table 4).

\section{Outcome Evaluation of Knowledge of Adolescents on Depression at 8-weeks Follow Up}

The knowledge of adolescents was measured on a 27-point rating scale and measured at 8weeks follow up. Results showed that the teacher-led, peer-led, teacher-led and peer-led educational intervention and control groups had mean \pm SD of $26.43 \pm 0.82,25.33 \pm 1.67$, $26.03 \pm 1.22$ and $12.97 \pm 3.35$ respectively. The results showed that the teacher-led educational intervention group had the highest mean among the groups. None of the adolescents in the intervention groups had low scores of depression knowledge during the follow-up evaluation (Table 5).

\section{Research Hypothesis}

There will be no significant difference in the level of knowledge of depression of in-school adolescents at baseline and 8-weeks follow-up period. The paired t-test was used to analyze the effect of the intervention on adolescents in the intervention groups. The intervention groups had the following results: teacher-led intervention [(effect size) $\mathrm{ES}=5.222 ; \mathrm{t}=19.943 ; p=$ 0.000]; peer-led intervention [(effect size $) \mathrm{ES}=3.540 ; \mathrm{t}=13.369 ; p=0.000$ ]; and combination 
of teacher-led and peer-led intervention [(effect size) $\mathrm{ES}=4.383, \mathrm{t}=18.137 ; p=0.000$ ] (Table $6)$.

\section{DISCUSSION}

The results from the study provide insight into the level of knowledge about depression among adolescents in the study area. According to the global mental health burden, 10-20 percent of adolescents suffer from at least one mental condition (Girma, Tsehay, Mamaru \& Abera, 2021). The total mean \pm SD ages of the adolescents in the teacher-led, peer-led, teacher- and peer-led and control groups were $14.43 \pm 2.315$ years, $14.33 \pm 1.605$ years, $14.97 \pm 1.426$ years and $15.43 \pm 1.960$ years respectively, which is similar to the age as established by Mogaji (2017) in the Southwest of Nigeria.

The study highlights that close to half of the respondents are not aware of depression. Previous studies have also underlined that lack of awareness about mental health issues and treatment alternatives, as well as a fear of stigma, discourage adolescents from seeking therapy and approaching the health-care system in the first place (Meredith et al., 2009; Hunt \& Eisenberg, 2010; Wilson, Deane, Marshall \& Dalley, 2010; Calear, Griffiths \& Christensen, 2011).

Baseline comparison of the level of adolescents' knowledge of depression in all groups indicated poor knowledge of depression. In line with previous research, a low percentage of depression detection was discovered. However, some of the respondents in this study had correct knowledge of depression, a number that is significantly lower than the $20-75 \%$ rate observed in studies conducted in developed nations (Dogra, Omigbodun, Adedokun, Bella, Ronzoni \& Adesokan, 2021; McCarthy, Bruno \& Fernandes, 2020). The current study's result of a considerably lower prevalence of depression literacy shows a significant unmet need for mental health literacy among Nigerian adolescents. Previous research revealed considerable misinformation and beliefs regarding mental illness among Nigerian adults (Lam, 2014).

The educative intervention modules had an impact on the adolescents' level of knowledge on depression. There was a significant increase in the level of knowledge of depression information across the intervention groups after the intervention was administered and the increased knowledge persisted over an 8-week follow-up period. In all intervention groups, no teenager had a low level of awareness of depression. Positive educational intervention should be implemented in schools to address the prevalence of depression (Seligman, 2015).

It is remarkable to note that the teacher-led intervention program had a higher effect size on the level of knowledge of adolescents on depression both at the impact intervention and at the 8 -weeks follow up compared to the other modules. These findings suggest that school teachers may be useful in delivering universal preventive programs for depression or mental health in general among adolescents (Lai et al., 2016; Mælan, Tjomsland, Samdal \& Turston, 2021).

Research (McCarthy, Bruno \& Fernandes, 2020) has shown that periodic and continuous interventions can be more effective for changing behaviour and lifestyle, because the change process does not occur only from information. One can also infer that the educational intervention was effective in raising awareness and also in increasing and sustaining the knowledge of adolescents in the study population. 


\section{Implications of Findings to Health Promotion and Education}

The major implication to health promotion and education this study has is that it has brought to light the importance and effectiveness of educational interventions for adolescents pertaining to depression and mental health which health educators can utilize. It was also documented that respondents' knowledge about depression was poor. In light of this, other forms of health promotion educational interventions tailored towards improving knowledge of depression concerning adolescents should not only be directed towards the adolescent but rather towards their older adults who are in charge of their life choices.

\section{CONCLUSION}

This study demonstrated that adolescents' knowledge towards depression could be changed through multi-approach educational intervention. The teacher-led educational intervention had the greatest effect size and change in the level of adolescents' depression knowledge. This study further reiterates the opinion that teachers are often able to provide adolescents with the necessary support. They also play the role of mentors in schools, which makes adolescents more likely to accept the support that they provide.

\section{Future Research}

There is a need for further studies to explore both the qualitative and quantitative approach in investigating teacher-student relationships on mental health issues, such as depression, in Africa. Researchers should also reach out targeting out-of-school adolescents in improving their depression knowledge and perception.

Table 1: Baseline Distribution of Socio-Demographic Characteristics of Adolescents in the Control and Intervention Groups: Age, Gender, Class and Religion

\begin{tabular}{|c|c|c|c|c|c|}
\hline Variables & $\begin{array}{c}\text { TL } \\
\mathbf{N}(\%)\end{array}$ & $\begin{array}{c}\text { PL } \\
\mathbf{N}(\%)\end{array}$ & $\begin{array}{l}\text { T\&PL } \\
\text { N (\%) }\end{array}$ & $\begin{array}{c}\text { Control } \\
\mathbf{N}(\%)\end{array}$ & $\begin{array}{c}\text { p- } \\
\text { value }\end{array}$ \\
\hline \multicolumn{6}{|l|}{ Age in years } \\
\hline $10-13$ & $10(33.3)$ & $8(26.7)$ & $3(10)$ & $4(13.3)$ & $0.312^{\mathrm{a}}$ \\
\hline 14-16 & $14(46.7)$ & $20(66.7)$ & $23(78.7)$ & $19(63.3)$ & \\
\hline $17-19$ & $6(20)$ & $2(8.7)$ & $4(13.3)$ & $7(23.3)$ & \\
\hline Total & $30(100)$ & $30(100)$ & $30(100)$ & $30(100)$ & \\
\hline Mean \pm SD & $\mathbf{1 4 . 4 3} \pm 2.315$ & $14.33 \pm 1.605$ & $\mathbf{1 4 . 9 7} \pm 1.426$ & $15.43 \pm 1.960$ & \\
\hline \multicolumn{6}{|l|}{ Gender } \\
\hline Female & $15(50)$ & $19(63.3)$ & $19(63.3)$ & $16(53.3)$ & $0.806^{\mathrm{a}}$ \\
\hline Male & $15(50)$ & $11(36.7)$ & $11(36.7)$ & $14(47.7)$ & \\
\hline Total & $30(100)$ & $30(100)$ & $30(100)$ & $30(100)$ & \\
\hline
\end{tabular}




\begin{tabular}{cccccc}
\hline Class & & & & \\
JSS 1 & $4(13.3)$ & $6(20)$ & $0(0)$ & $5(16.7)$ & $0.901^{\mathrm{a}}$ \\
JSS 2 & $7(23.3)$ & $7(23.3)$ & $5(16.7)$ & $7(23.3)$ & \\
JSS 3 & $4(13.3)$ & $5(16.7)$ & $9(30.0)$ & $0(0)$ & \\
SSS 1 & $5(16.7)$ & $7(23.3)$ & $16(53.3)$ & $12(40.0)$ & \\
SSS 2 & $10(33.3)$ & $5(16.7)$ & $0(0)$ & $6(20)$ & \\
Total & $\mathbf{3 0}(\mathbf{1 0 0})$ & $\mathbf{3 0}(\mathbf{1 0 0})$ & $\mathbf{3 0}(\mathbf{1 0 0})$ & $\mathbf{3 0}(\mathbf{1 0 0})$ & \\
& & & & \\
Religion & & & & & \\
Christianity & $25(83.3)$ & $28(93.3)$ & $15(50)$ & $26(88.7)$ & $0.405^{\mathrm{a}}$ \\
Islam & $5(16.7)$ & $1(3.3)$ & $15(50)$ & $4(13.3)$ & \\
Traditional & $0(0)$ & $1(3.3)$ & $0(0)$ & $0(0)$ & \\
Total & $\mathbf{3 0}(\mathbf{1 0 0})$ & $\mathbf{3 0}(\mathbf{1 0 0})$ & $\mathbf{3 0}(\mathbf{1 0 0})$ & $\mathbf{3 0}(\mathbf{1 0 0})$ & \\
\hline
\end{tabular}

${ }^{a} \mathrm{p}$-value obtained by Chi-square test

Table 2: Baseline Distribution of Socio-Demographic Characteristics of Adolescents in the Control and Intervention Groups: Ethnic Group and Parents' Marital Status

\begin{tabular}{cccccc}
\hline Variables & TL & $\mathbf{P L}$ & $\mathbf{T \& P L}$ & $\begin{array}{c}\text { Control } \\
\mathbf{N}(\boldsymbol{\%})\end{array}$ & p-value \\
\hline Ethnic Group & $\mathbf{N}(\boldsymbol{\%})$ & $\mathbf{N}(\boldsymbol{\%})$ & $\mathbf{N}(\mathbf{\%})$ & & \\
Yoruba & $29(96.7)$ & $27(90.0)$ & $27(90)$ & $16(53.3)$ & $0.000^{\mathrm{a}}$ \\
Igbo & $1(3.3)$ & $1(3.3)$ & $1(3.3)$ & $6(20)$ & \\
Hausa & $0(0)$ & $0(0)$ & $1(3.3)$ & $0(0)$ & \\
Others & $0(0)$ & $2(6.7)$ & $1(3.3)$ & $8(26.7)$ & \\
Total & $\mathbf{3 0}(\mathbf{1 0 0})$ & $\mathbf{3 0}(\mathbf{1 0 0})$ & $\mathbf{3 0}(\mathbf{1 0 0})$ & $\mathbf{3 0}(\mathbf{1 0 0})$ & \\
& & & & \\
Parents' Marital & & & & & \\
Status & & & & & \\
Single & $0(0)$ & $3(10)$ & $1(3.3)$ & $27(90)$ & $0.926^{\mathrm{a}}$ \\
Married & $27(90)$ & $27(90)$ & $28(93.3)$ & $0(0)$ & \\
Divorced & $1(3.3)$ & $0(0)$ & $0(0)$ & $2(6.7)$ & \\
Widowed & $2(6.7)$ & $0(0)$ & $1(3.3)$ & $1(3.3)$ & \\
Total & $\mathbf{3 0}(\mathbf{1 0 0})$ & $\mathbf{3 0}(\mathbf{1 0 0})$ & $\mathbf{3 0}(\mathbf{1 0 0})$ & $\mathbf{3 0}(\mathbf{1 0 0})$ & \\
\hline
\end{tabular}

${ }^{\mathrm{a} p}$-value obtained by Chi-square test 
Table 3: Baseline Comparison of the Level of Adolescents' Knowledge of Depression in the Control and Intervention Groups

\begin{tabular}{llllll}
\hline Variables & TL & PL & TL\&PL & Control & p-value \\
& N $(\%)$ & N $(\%)$ & N $(\%)$ & N $(\%)$ & \\
\hline $\begin{array}{l}\text { Knowledge } \\
\text { Poor } \\
(0-13.5)\end{array}$ & $\begin{array}{l}\text { Measured } \\
\text { Gon a 27-point Rating Scale }\end{array}$ & & & \\
$\begin{array}{l}\text { Good } \\
(13.51-27)\end{array}$ & $11(36.3)$ & $18(60.0)$ & $17(56.7)$ & $21(70.0)$ & $0.323^{\mathrm{a}}$ \\
$\begin{array}{l}\text { Total } \\
\text { Mean } \pm \text { SD }\end{array}$ & $12(40.0)$ & $13(43.3)$ & $9(30.0)$ & \\
\hline
\end{tabular}

${ }^{a}$ p-value obtained by One-way ANOVA test

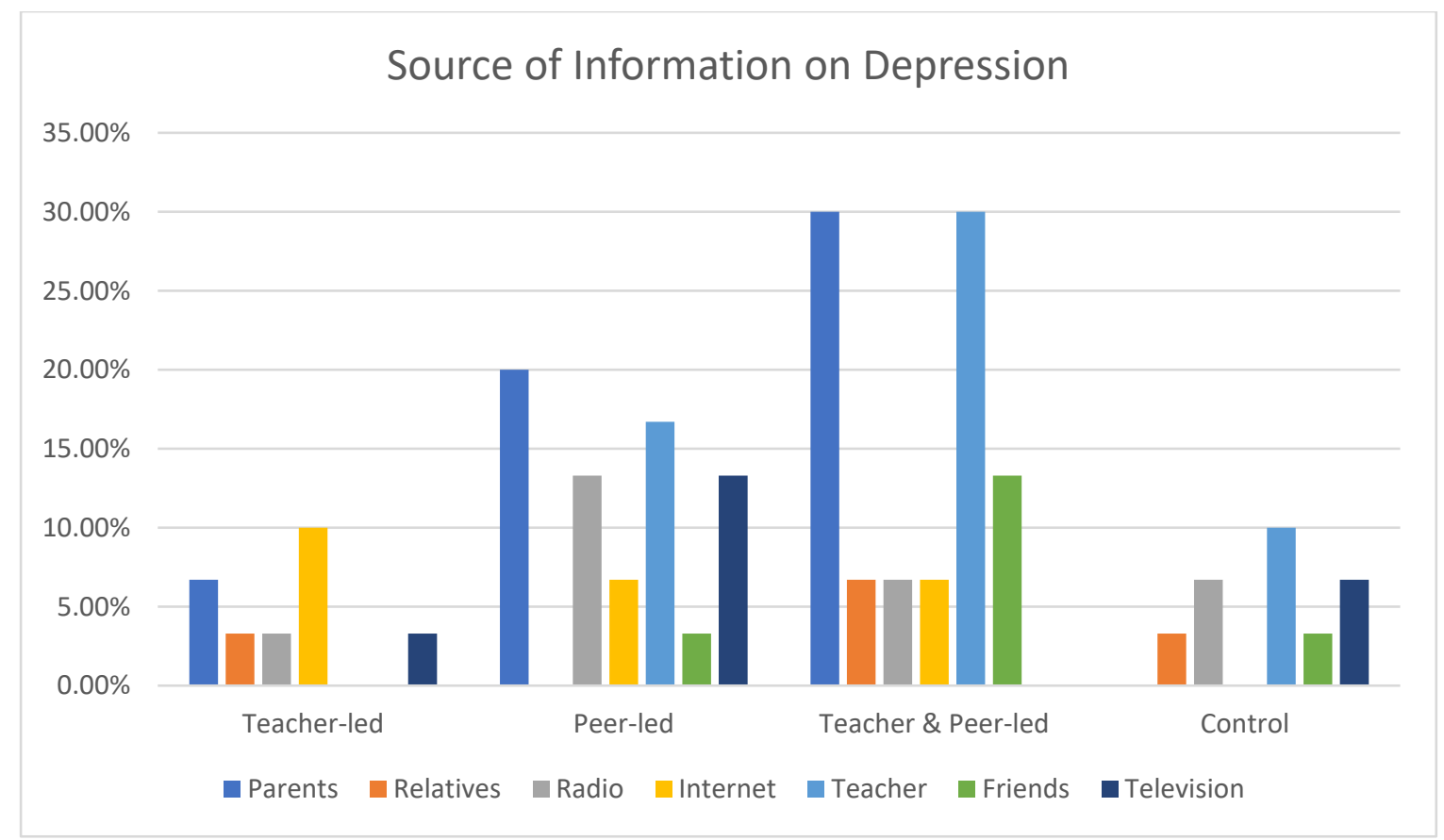

Figure 1: Distribution of Adolescents' Source of Information on Depression 
Table 4: Comparison of Adolescents' Level of Depression Knowledge at Immediate Post Intervention for Intervention and Control Groups

\begin{tabular}{lcccccc}
\hline Variable & $\begin{array}{c}\text { Maximum } \\
\text { Score }\end{array}$ & $\begin{array}{c}\text { Teacher- } \\
\text { Led }\end{array}$ & Peer-Led & $\begin{array}{c}\text { Teacher \& } \\
\text { Peer-Led }\end{array}$ & Control & $\begin{array}{c}\text { p- } \\
\text { value }\end{array}$ \\
\hline $\begin{array}{l}\text { Knowledge } \\
\text { Poor }(0-\end{array}$ & 27 points & $0(0.0)$ & $0(0.0)$ & $0(0.0)$ & $19(63.3)$ & $0.000^{*}$ \\
$\begin{array}{l}13.5) \\
\begin{array}{l}\text { Good } \\
(13.51-27)\end{array}\end{array}$ & & $30(100.0)$ & $30(100.0)$ & $30(100.0)$ & $11(46.7)$ & \\
Mean \pm SD & & $26.20 \pm 0.96$ & $25.20 \pm 1.73$ & $25.70 \pm 1.46$ & $\begin{array}{c}12.70 \pm 3.2 \\
5\end{array}$ & \\
\hline
\end{tabular}

p-values obtained by One-way ANOVA

*Significant at $<0.05$

Table 5: Comparison of Adolescents' Level of Depression Knowledge at 8th-week Followup for Intervention and Control Groups

\begin{tabular}{lcccccc}
\hline Variable & $\begin{array}{c}\text { Maximu } \\
\text { m Score }\end{array}$ & $\begin{array}{c}\text { Teacher- } \\
\text { Led }\end{array}$ & Peer-Led & $\begin{array}{c}\text { Teacher \& } \\
\text { Peer-Led }\end{array}$ & Control & $\begin{array}{c}\text { p- } \\
\text { value }\end{array}$ \\
\hline Knowledge & & & & & & \\
Poor (0-13.5) & 27 points & $0(0.0)$ & $0(0.0)$ & $0(0.0)$ & $18(60.0)$ & $0.000^{*}$ \\
Good (13.51-27) & & $30(100.0)$ & $30(100.0)$ & $30(100.0)$ & $12(40.0)$ & \\
Mean \pm SD & & $\mathbf{2 6 . 4 3} \pm \mathbf{0 . 8 2}$ & $\mathbf{2 5 . 3 3 \pm \mathbf { 1 . 6 7 }}$ & $\mathbf{2 6 . 0 3} \pm \mathbf{1 . 2 2}$ & $\mathbf{1 2 . 9 7} \pm \mathbf{3 . 3 5}$ & \\
\hline
\end{tabular}

p-values obtained by One-way ANOVA

*Significant at $<\mathbf{0 . 0 5}$

Table 6: Paired T-Test Analysis Showing the Difference in Mean between Adolescents' Level of Depression Knowledge between Baseline and 8th-week Follow-up

\begin{tabular}{|c|c|c|c|c|c|c|c|}
\hline Groups & $\overline{\mathrm{x}}(\mathrm{SE})$ & SD & $\begin{array}{c}\text { Mean } \\
\text { Difference }\end{array}$ & $\mathrm{ES}(\mathrm{CI})$ & df & $\mathrm{t}$ & $\begin{array}{c}\mathrm{p}- \\
\text { value }\end{array}$ \\
\hline \multicolumn{8}{|l|}{$\begin{array}{l}\text { Teacher-Led } \\
\text { Intervention } \\
\text { Group }\end{array}$} \\
\hline Baseline & $\begin{array}{l}11.57 \\
(0.73)\end{array}$ & $\begin{array}{c}4.0 \\
1\end{array}$ & 14.87 & $\begin{array}{c}5.222 \\
(4.502- \\
5.942)\end{array}$ & $\begin{array}{l}2 \\
9\end{array}$ & $\begin{array}{c}19.94 \\
3\end{array}$ & 0.000 \\
\hline $\begin{array}{l}\text { 8th-week } \\
\text { Follow-up } \\
\text { Peer-Led } \\
\text { Intervention } \\
\text { Group }\end{array}$ & $\begin{array}{l}26.43 \\
(1.18)\end{array}$ & $\begin{array}{c}0.8 \\
2\end{array}$ & & & & & \\
\hline 80 & & & $\begin{array}{l}\text { icle DOI: } 10.5 \\
\text { I URL: https:// }\end{array}$ & $\begin{array}{l}\text { PHP-QJO } \\
/ 10.52589\end{array}$ & $\begin{array}{l}\mathrm{EF} \\
\mathrm{HP}-\mathrm{C}\end{array}$ & OZLVEF & \\
\hline
\end{tabular}




\begin{tabular}{lccccccc}
\hline Baseline & 13.47 & 4.5 & 11.87 & 3.540 & 2 & 13.36 & 0.000 \\
8th-week & $(0.76)$ & 2 & & $(2.69-4.38)$ & 9 & 9 & \\
$\begin{array}{l}\text { Follow-up } \\
\text { Teacher-Led and }\end{array}$ & 25.33 & 1.6 & & & & & \\
$\begin{array}{l}\text { Peer-Led } \\
\text { Intervention }\end{array}$ & & $0.30)$ & 7 & & & & \\
Groups & & & & & & & \\
Baseline & 12.83 & 4.1 & 13.20 & 4.383 & 2 & 18.13 & 0.000 \\
8th-week & $(0.76)$ & 5 & & $(3.62-5.14)$ & 9 & 7 & \\
Follow-up & 26.03 & 1.2 & & & & & \\
Control Group & $(0.22)$ & 2 & & & & & \\
Baseline & 12.63 & 3.1 & 0.33 & $0.106(071-$ & 2 & 0.471 & 0.106 \\
8th-week & $(0.58)$ & 8 & & $0.92)$ & 9 & & \\
Follow-up & 12.97 & 3.3 & & & & & \\
\hline
\end{tabular}

\section{Ethical Considerations}

The study obtained ethical approval from the ethical committee of the university-Babcock University Health Research and Ethics Committee (BUHREC), and also from the Ministry of Health Research Ethics Review Committee and the Ministry of Education Planning Research and Statistics, Ogun State, Nigeria, in order to conduct the study. Informed consent was obtained from all respondents and their parents/guardians before administering the questionnaires. Confidentiality of every information provided was duly kept discrete and the instrument was administered to participants anonymously without requiring the names of the respondents.

\section{Acknowledgements}

I would like to acknowledge the Almighty God for his sovereignty over my life; may his name be praised; I will be forever grateful. The $\mathrm{PhD}$ thesis was a challenging but valuable learning experience. I thank the Almighty God for helping me to complete it successfully. I am very grateful to my supervisor, for his guidance, constructive criticism and constant encouragement right from the preparation, data collection stages, and throughout the writing of this thesis. I wish to thank all teachers, parents and adolescents who consented to participate in this study, without whom this thesis would not have been possible. My sincere thanks also go to my parents, Engr. Mr. and Engr. Mrs. O. Uzoechi, for assisting and providing the funding for the work, and my siblings, Chika and Chibuikem Uzoechi. 


\section{REFERENCES}

Adeosun, I. B., Adegbhoun, A. A., Jeje, O. O., Bello, A. O., \& Manuwa, O. O. (2015). Perceived barriers to help seeking for psychosis among secondary school students, Lagos, Nigeria. British Journal of Education, Society and Behavioural Science, 9(2), 153-160. https://doi:10.9734/BJESBS/2015/18060

Aluh, D. O., Abba, A., \& Afosi, A. B. (2020). Prevalence and correlates of depression, anxiety and stress among undergraduate pharmacy students in Nigeria. Pharmacy Education, 20(1), 236-248. https://doi.org/10.46542/pe.2020.201.236248

Becker, M. H. (1974). The Health Belief Model and Personal Health Behaviour. Thorofare, N. J.: Charles B. Slack.

Burns, J. R., \& Rapee, R. M. (2017). Adolescent mental health literacy: Young people's knowledge of depression and help seeking. Journal of Adolescence, 29(2), 225-239. https://doi:10.1016/j.adolescence.2005.05.004

Calear, A. L., Griffiths, K. M., \& Christensen, H. (2011). Personal and perceived depression stigma in Australian adolescents: magnitude and predictors. Journal of Affective Disorders, 129(1-3), 104-108.

Dapaah, J. M., \& Amoako, H. A. F. (2019). The causes of depression among university students and its effects on their academic life in the Kwame Nkrumah University of Science and Technology, Kumasi, Ghana. International Journal for Innovation Education and Research, 7(6), 154-167. https://doi.org/10.31686/ijier.vol7.iss6.1504

Dogra, N., Omigbodun, O., Adedokun, T., Bella, T., Ronzoni, P., \& Adesokan, A. (2021). Nigerian secondary school children's knowledge of and attitudes to mental health and illness. Clinical Child Psychology and Psychiatry, 17(3), 336-353.

Ekwe, C. N., \& Ohuakanwa, C. E. (2020). Psychotherapy and Counselling: Attitudes Toward Mental Health Seeking Services in Nigeria. International Journal for Psychotherapy in Africa, 2(1), 62-70. https://sphs.com.ng/wp-content/uploads/2019/12/PsychotherapyAnd-Counselling-Attitudes-Toward-Mental-Health-Seeking-Services-In-Nigeria.pdf

Girma, S., Tsehay, M., Mamaru, A., \& Abera, M. (2021). Depression and its determinants among adolescents in Jimma town, Southwest Ethiopia. Public Library of Science One, 16(5), e0250927. https://doi.org/ 10.1371/journal.pone.0250927

Goyal, M., Kohli, C., Kishore, J., \& Jiloha, R. C. (2013). Effect of an Educational Booklet on Knowledge and Attitude Regarding Major Depressive Disorder in Medical Students in Delhi. International Journal of Medical Students, 1(1), 16-23. https://doi.org/10.5195/ijms.2013.17

Hochbaum, G. (1958). Public Participation in Medical Screening Programs: a sociopsychological study. (Public Health Service Publication No. 572). Washington, D.C. Government Printing Office. https://www.worldcat.org/title/public-participation-inmedical-screening-programs-a-socio-psychological-study/oclc/9471787

Hunt, J., \& Eisenberg, D. (2010). Mental health problems and health-seeking behavior among college students. Journal of Adolescent Health, 46(1), 3-10.

James, S. L., Abate, D., Abate, K. H., Abay, S. M., Abbafati, C., Abbasi, N., ... \& Abdollahpour, I. (2018). Global, regional, and national incidence, prevalence, and years lived with disability for 354 diseases and injuries for 195 countries and territories, 1990-2017: a systematic analysis for the Global Burden of Disease Study 2017. The Lancet, 392(10159), 1789-1858. https://doi:10.1016/S0140-6736(18)32279-7

Labinjo, T., Serrant, L., Ashmore, R., \& Turner, J. (2020). Perceptions, attitudes and cultural understandings of mental health in Nigeria: a scoping review of published 
literature. Mental Health, Religion \& Culture, 23(7), 606-624. https://doi.org/10.1080/13674676.2020.1726883

Lai, E. S., Kwok, C. L., Wong, P. W., Fu, K. W., Law, Y. W., \& Yip, P. S. (2016). The effectiveness and sustainability of a universal school-based programme for preventing depression in Chinese adolescents: A follow-up study using quasi-experimental design. Public Library of Science One, 11(2), e0149854. https://doi.org/10.1371/journal.pone.0149854

Lam, L. T. (2014). Mental health literacy and mental health status in adolescents: A population-based survey. Child and Adolescent Psychiatry and Mental Health, 8(1), 26. https://doi:10.1186/1753-2000-8-26

Mælan, E. N., Tjomsland, H. E., Samdal, O., \& Thurston, M. (2020). Pupils' perceptions of how teachers' everyday practices support their mental health: A qualitative study of pupils aged 14-15 in Norway. Scandinavian Journal of Educational Research, 64(7), 1015-1029. https://doi.org/10.1080/00313831.2019.1639819

McCarthy, J., Bruno, M., \& Fernandes, T. E. (2020). Evaluating Mental Health Literacy and Adolescent Depression: What Do Teenagers" Know?". Professional Counselor, 1(2), 133-142.

Meredith, L. S., Stein, B. D., Paddock, S. M., Jaycox, L. H., Quinn, V. P., Chandra, A., \& Burnam, A. (2009). Perceived barriers to treatment for adolescent depression. Medical Care, 677-685.

Mogaji, M. O. (2017). Factors Associated with Depression and Help-Seeking Behaviour Among In-School Adolescents in Ibadan North Local Government Area, Oyo State (Masters Dissertation). African Digital Health Library, 1(1), https://adhlui.com.ui.edu.ng/jspui/handle/123456789/319

National Institute of Mental Health, NIMH, 2018. https://www.nimh.nih.gov/health/topics/depression/index.shtml

Naylor, P. B., Cowie, H. A., Walters, S. J., Talamelli, L., \& Dawkins, J. (2019). Impact of a mental health teaching programme on adolescents. The British Journal of Psychiatry, 194(4), 365-370. https://doi:10.1192/bjp.bp.108.053058

Rosenstock, I. M. (1966). Why people use health services. Milbank Memorial Fund Quarterly, 44(3), 94-124. https://doi.org/10.1111/j.1468-0009.2005.00425.x

Saxena, S., Thornicroft, G., Knapp, M., \& Whiteford, H. (2017). Resources for mental health: scarcity, inequity, and inefficiency. The Lancet, 370(9590), 878-889. https://doi.org/10.1016/S0140-6736(07)61239-2

Seligman, M. (2015). Evidence-based approaches in positive education: Implementing a strategic framework for well-being in schools. Springer.

Sharma, M., \& Romas, J. A. (2012). Theoretical Foundations of Health Education and Health Promotion. London: Jones and Bartlett Learning. https://www.medsab.ac.ir/uploads/1_(4)_46099.pdf

Wilson, C. J., Deane, F. P., Marshall, K. L., \& Dalley, A. (2010). Adolescents' suicidal thinking and reluctance to consult general medical practitioners. Journal of Youth and Adolescence, 39(4), 343-356.

World Health Organization (2020). Depression. Fact sheet. https://www.who.int/newsroom/fact-sheets/detail/depression/ 